\title{
Research on Prevention, Punishment Mechanism and Perfect Direction of Corruption Crimes in Government Procurement in China
}

\author{
Pujun Liu \\ Central University of Finance and Economics, School of Finance and Taxation, 102206
}

Keywords: Government Procurement, Pre-Punishment, Blacklist, Disqualification, Criminal Policy

\begin{abstract}
The prevention mechanism of corruption crimes in the field of government procurement in China is composed of the blackmail system under the framework of administrative law and the file system for filing bribery crimes under the criminal justice framework. The punishment mechanism for corruption crimes in government procurement is dependent on criminal law, and achieves sanctions for corruption offences. However, the disqualification mechanism in the field of foreign government procurement is still in a state of long-term system vacancy in China. At the same time, under the influence of the inertia of "paying attention to the crime of accepting bribes and ignoring the blow of bribery crimes", bribery crimes have not been effectively punished. It can be seen that it is of practical significance to consider the perfect direction of the prevention and punishment mechanism of corruption crimes in the field of government procurement in China.
\end{abstract}

\section{Introduction}

With the development of China's government procurement system, the scale of government procurement has been enlarged year by year, and the huge hidden interests in the field of government procurement have caused more and more corruption crimes to invade and the government's credibility has been destroyed. Therefore, it is of great significance to face up to the risk of corruption crimes in the field of government procurement, to examine the predicament and shortcomings of the current prevention and punishment mechanism, and to consider the feasibility of reducing corruption crimes in our government.

\section{Risk of Corruption Crimes in the Field of Government Procurement in China}

\subsection{The Overall Performance of Corruption Crimes in the Field of Government Procurement}

China's government procurement is huge. According to the data released by the Ministry of Finance, the national government procurement scale exceeded 2 trillion yuan for the first time in 2015, reaching 2,107.05 billion yuan. In 2016, the national government procurement scale reached 2,571.4 billion yuan. The huge scale of government procurement means huge business opportunities in the field of government procurement. Under the influence of interests, the government procurement field will inevitably become a high-risk place for corruption crimes. Researcher Lin Yueqin pointed out in an interview: "There is an authoritative statistical data showing that in the second half of the 1990s, the corruption losses in government procurement contracts averaged between 98.75 billion yuan and 135 billion yuan, accounting for 13.2\% of the country's total GDP. To 16.8\%, government procurement has become a field of corruption and high incidence. In short, as a whole, corruption crimes in the field of government procurement in China have the characteristics of high crime frequency and high crime. The author uses the "government procurement" as the key to search in the legal case retrieval platform of Peking University. Through the screening of criminal cases, it is found that there are 2,460 criminal cases related to government procurement under the crime of corruption and bribery. 217 criminal cases are associated with government procurement. Judging from the trial year, since 2014, the number of corruption crimes related to government procurement has remained high, and 2017 has reached 787, which is five times the number of cases handled in 2013. It can be seen that the high incidence of corruption 
crimes in the field of government procurement in China has been formed. It is extremely urgent to improve the front-end prevention mechanism and the back-end sanctions of corruption crimes in the field of government procurement in China.

\subsection{The Prone to Corruption Crimes in the Field of Government Procurement}

From the perspective of the breeding grounds of corruption crimes, corruption crimes in various aspects of government procurement procedures have infiltrated into different degrees. Specifically, the first is the demand confirmation link. In the demand determination process, the supplier can exchange the exclusive status through the interest transfer, so as to obtain the qualification of the winning candidate supplier. The so-called exclusive status, that is, the purchaser can set unreasonable specific conditions and receive the supply that does not meet the specific conditions after receiving the benefit. Excluded from the procurement project, suppliers who implement bribery have thus obtained an exclusive status that excludes other suppliers' fair competition and equal participation rights. The second is the selection of procurement methods. In the procurement method selection section, although there are six types of government procurement methods specified in Article 26 of the Government Procurement Law, and Article 27 provides for procurement in procurement methods other than public bidding, it shall be supervised by the procurement supervision before the procurement activities begin. However, in practice, the situation of suppliers, purchasers, and regulators colluding with each other occurs from time to time. Among them, the interest transfer is a bond that is closely related to each other, thus avoiding open tendering and reaching specific suppliers by means of non-public tendering. The third is the evaluation and calibration process. In the evaluation and calibration process, the supplier can influence the final score of the evaluation expert through the benefit transfer, so as to obtain the qualification of the winning candidate supplier. The fourth is the performance acceptance check. In the compliance acceptance process, the more common manifestation of corruption crimes is that the supplier delivers benefits to the purchaser, so that the purchaser can lower the acceptance criteria in the fulfillment of the procurement contract, and the situation of sub-filling, inferiority, and indiscriminate It's rare. All in all, the risk of corruption crimes in the field of government procurement runs through many aspects of the government procurement process. On the one hand, it reflects the pervasive development trend of corruption crimes in the field of government procurement, and on the other hand, it reflects the administrative and criminal aspects in China. From the perspective of meta-policy, the effective anti-punishment mechanism of corruption crimes remains to be explored. The demand for effective reduction of corruption crimes in the field of government procurement in China is particularly urgent.

\section{The Defect Correction of Corruption Crimes in the Field of Government Procurement in China}

\subsection{Front-End Prevention Perspective: the Systematic Absence of the Disqualification Mechanism}

In recent years, the blackmail system for blackmail and the bribery crime file query system have played a part in the role of the cancellation mechanism in the field of government procurement. However, compared with the current situation of foreign government procurement system, the system of Disqualification mechanism is in the government of our country. The vacancy situation in the procurement field is undeniable. The problem is that the crackdown on corruption crimes in China's government procurement field is increasingly dependent on criminal punishment, and it turns out that it relies too much on the general prevention function of criminal law. To reduce the effectiveness of corruption crimes in government procurement, the unique value of the Disqualification mechanism should not be ignored.

Foreign experience: the Disqualification mechanism in the field of foreign government procurement. From an international perspective, whether it is a developed country or a developing country, the construction of anti-corruption mechanisms undoubtedly occupies the most central 
position in the country's legislative construction, and as the hardest hit area of corruption crimes the anti-corruption mechanism in the field of government procurement The construction of this is undoubtedly the most important thing. In this context, the Disqualification mechanism came into being and gradually developed into an important mechanism for preventing corruption crimes in government procurement, which is widely accepted by governments.

What is the Disqualification mechanism? Disqualification is a specialized prevention mechanism created in the field of foreign government procurement for corruption offences. The "Disqualification mechanism" is the unified title used in this paper to simplify the formulation, but in different countries, the title of the Disqualification mechanism It is not the same, although there is no significant difference in the substance behind these titles. In the field of foreign government procurement, suppliers should trigger the Disqualification mechanism and be excluded from the threshold of government procurement. The attitudes of countries around the world are different. Generally speaking, they can be classified into the following three types. Type: First, if a supplier has a violation of legal, ethical, and anti-corruption rules, it should be excluded. Second, if a supplier violates the rules of the government procurement process in a particular government procurement process, it should Excluded; third, if the supplier has a situation that has violated government procurement rules, it should be excluded. For the above three types of Disqualification mechanisms, there are provisions in the relevant rules of the World Bank, and in the relevant rules of the United Kingdom and the European Union, the first type of Disqualification mechanism is the common choice of the two, in the relevant US rules. The Disqualification mechanism uses the first and third types mentioned above. All in all, in the field of government procurement in different countries, although the Disqualification mechanism has different triggering conditions, the Disqualification mechanism is an important means of preventing corruption crimes in the government procurement field.

Content and structure of the Disqualification mechanism. The regulations on the disqualification mechanism are similar in the world, and they have great similarities. The provisions of Article 57 of the Public Contract Law of the United Kingdom are very representative. Therefore, the author intends to introduce the field of foreign government procurement with the example of "excluding reasons". In the British "Public Contract Law 2015", the provisions of the "excluding reasons" section can be roughly divided into five aspects. The first part is "Mandatory exclusions". In the first part, the Public Contract Law 2015 lists crimes such as corruption crimes, fraud crimes, theft crimes, terrorist crimes, drug crimes, etc. as specific matters of compulsory exclusion. It can be seen that the mandatory exclusion is usually criminal. In addition, in the first part, the conditions for the application of the mandatory exclusion rule for unpaid taxes and the exceptions to the mandatory exclusion are also stipulated, and the mandatory exclusion rules are enriched and full. The second part is "Discretionary exclusions." Unlike discretionary exclusions, discretionary exclusions are not criminal offences, but are often ethical violations or contractual obligations. The third part is "Exclusion during procedure". In the third part, the procedure refers to the government procurement procedure. The items excluded in the procedure can also be divided into two cases: mandatory exclusion and discretionary exclusion. The situation is not different from the situation specified in the first part and the second part. The fourth part is the "Duration of exclusion". In the fourth part, the British "Public Contract Law 2015" sets the exclusion period for mandatory exclusion and discretionary exclusion, and the exclusion period for mandatory exclusion is 5 years. The exclusion period for discretionary exclusion is 3 years. The fifth part is "Self-cleaning". In the fifth part, the British "Public Contract Law 2015" is a procedure for the operator to set aside the exclusion reason, and detailed the operators. It is necessary to prove the specific content of the self-inspection and rectification conditions.

Existing exploration: from the blacklist system of dishonesty to the file system for bribery crimes. In the face of the shackles of corruption crimes, in order to achieve fairness in market transactions, China's administrative organs and criminal justice organs have actively explored the prevention mechanism of corruption crimes from their respective perspectives and gained many useful experiences. 
Existing exploration within the administrative framework. In China's social credit system, the blacklist system of dishonesty is an important part of it. The "Guiding Opinions of the State Council on Establishing and Improving the Joint Incentives for Trustworthiness and the Joint Disciplinary System for Distrust and Accelerating the Construction of Social Credit" clearly pointed out that the system of "red list" for integrity and the "blacklist" system for serious untrustworthy entities should be continuously improved, and various fields should be regulated according to law. The red and black lists are generated and released, and a sound exit mechanism is established. "Guiding Opinions on Strengthening and Standardizing the Joint Incentives and Trustworthy Joint Disciplinary Objects Management (Consultation Draft)" also pointed out that a sound red and black list management and application system will be established, and a unified definition of red and black lists in relevant fields will be formulated. Prudently identify the red and black list. For the units or individuals who are listed on the blacklist of untrustworthy blacklists, social forces will conduct joint punishment. At the same time, the exploration of the construction of the social credit system at the national level also promoted and promoted the introduction of local rules, such as the "Wuzhou City Social Organization's Blacklist Management Method (Trial)", the first place to open local rules, "Zhejiang social organization lost faith" black The list of "Management Measures (Trial)", "Zhengzhou City Social Organization Blacklist and Abnormal Directory Management Measures" and other local rules have been actively followed up, and the successive introduction of local rules has made the blackmail system of the blackmail more operable, and the effectiveness of the system has been Really released.

Existing exploration within the criminal framework. On February 6, 2013, the "Regulations on the Archives of Bribery Crimes Filed by the Supreme People's Procuratorate" was promulgated and implemented, and played an active role in curbing corruption crimes, especially in the prevention of corruption crimes in government procurement, engineering construction, and public resources. In fact, the judicial authorities' exploration of the bribery crime file search system was first carried out by the Beilun District Procuratorate of Ningbo City, Zhejiang Province in 2002. In the "Measures for the Bribery Blacklist System in the Beilun District Procuratorate of Ningbo City", "British Black" The list was first established. Subsequently, the blacklist of bribery was promoted and applied by the Zhejiang Provincial People's Procuratorate as a useful experience. The blacklist of bribery is the early title of the bribery crime file inquiry system. In April 2004, following the blacklist of bribery in Zhejiang Province, the Supreme People's Procuratorate, the Ministry of Construction, the Ministry of Communications and the Ministry of Water Resources jointly issued the "Criminal Crimes in the Field of Engineering Construction". According to the notice, in addition to Zhejiang Province, the bribery file enquiry system will select five regions to carry out pilot work nationwide. At this point, the bribery blacklist has completed the change of title, "criminal file inquiry" As the title of the system was confirmed, this change cast a strong subjective evaluation color in the blacklist title of bribery, and then developed into a more objective title, that is, the file system for bribery crimes is still in use today. With the continuous deepening of the pilot work and the continuous accumulation of relevant experience, the realistic conditions for establishing a nationwide bribery archives inquiry system are already in place. On January 1, 2006, the inquisition of bribery crime files was officially launched nationwide. In March of the same year, the Supreme People's Procuratorate issued the Interim Provisions on the Acceptance of Bribery Crimes, and the relevant implementation rules for bribery crime files were followed. Be clear. In February 2013, with the promulgation of the "Provisions of the Supreme People's Procuratorate's Bribery Crime Archives Enquiry Work", China's bribery crime file search system became more mature. From the perspective of front-end prevention of corruption crimes in the field of government procurement, the system of filing bribery crime files can be regarded as a positive response of the judicial organs in China to the increasingly rampant corruption crimes. It is a corruption crime prevention mechanism with the nature of "inspection recommendations". Under the background of the overall lack of Disqualification mechanism in government procurement, the creation of the bribery crime file inquiry system has filled the short-term prevention of corruption crime front-end in China, and accumulated the chinization of the cancellation mechanism of 
government procurement in China.

There are still shortcomings: the dilemma of applying the existing system in the field of government procurement in China. Compared with the Disqualification mechanism widely used in foreign government procurement, the existing blackmail system in the administrative management perspective and the existing bribery crime file query system in the criminal justice perspective still have many dilemmas that are difficult to apply to the government procurement field.

There are still shortcomings in the blackmail system. China's existing blacklist system for dishonesty is in a state of lack of top-level design of central documents, and the lack of uniformity of local documents, so that the system of blacklists for untrustworthiness applies to the obstacles in the field of government procurement.

The existing documents at the central level are mainly based on principled and guiding content, focusing on the important value and significance of the system of blackmail blacklisting. However, the existing documents on the specific content of the blackmail system are rarely involved, and the defects of the top design the direct result is that the local rules show the status of "respectively in politics" and "different punishments of colleagues" are not uncommon in different local rules. The existing documents at the local level have different provisions on the blacklist system for dishonesty in different regions. Therefore, whether it is from the central level or the local level, the existing blackmail system has many defects. It is difficult to apply it to the government procurement field. It is imperative to systematically consider the front-end prevention mechanism of corruption crimes in government procurement. .

There are still shortcomings in the file system for bribery crimes. China's bribery crime file search system is not impeccable for the application of China's government procurement field. Compared with the Disqualification mechanism, there are still many shortcomings to be improved.

In China's bribery crime file inquiry system, the role played by the people's procuratorate is usually the creator of the bribery crime archive, the acceptor of the bribery crime file search application, and the provider of the bribery crime file query result, and the reason for the inquiry procedure is initiated. The specific scope of the inquiry subject and the application of the query result are subject to greater arbitrariness and lack of coercive protection.

Article 23 of the Provisions of the Supreme People's Procuratorate on the Enquiry of Bribery Crimes stipulates that: "The period of inquiry for bribery crime information is 10 years." This means that regardless of the sentence imposed by the offender for bribery, the offender The time limit for filing bribery crime files is 10 years. That is to say, the perpetrator was sentenced to three years in prison for bribery and sentenced to 10 years in prison. The effect of the bribery crime file is the same. The perpetrator was sentenced to criminal detention and sentenced to fixed-term imprisonment for bribery. From the point of view of the filing period of bribery crime files, the effect is also equivalent, which obviously ignores the ups and downs of the harmfulness of bribery crimes under different circumstances.

In China's bribery crime file query system, the scope of the inquiry subject is set too broad, and the privacy of the bribery crime file is insufficient. In the field of government procurement, the broad scope of the subject of the inquiry means that the offender may be over-evaluated as a result.

\subsection{The Angle of Back-end Sanctions: Thinking Inertia and Cognitive Bias in Criminal Policy Change}

Under the "zero tolerance" high-pressure anti-corruption situation, China's anti-corruption work has achieved remarkable results in recent years. However, in the face of excellent anti-corruption transcripts, it should be clearly understood that under the current criminal policy against corruption, the concept of criminal justice still lags behind the change of criminal policy. In the judicial practice, the judicial personnel still adhere to the traditional criminal policy. Among them, the more prominent problem is that under the influence of the traditional criminal policy of "taking bribes and bribery", the effect of bribery crimes is not satisfactory. Some scholars have conducted a quantitative analysis of the data on bribery crimes investigated and conducted by the People's Procuratorate from 2000 to 2014. The conclusions can clearly reflect the lag of criminal justice in 
several criminal policy changes. According to the statistics of the scholars, from 2008 to 2014, the number of people involved in bribery crimes in the People's Procuratorate accounted for $10.75 \%$ and $14.20 \%$ of the total number of crimes committed in various types in the whole year, and remained at $10 \%$. The following shares, in contrast, the number of bribery crimes in the same period accounted for the percentage of crimes in various types of duty in the whole year, but up to about 25.06\%. Obviously, under the influence of the inertia of " Pay attention to the crime of accepting bribes and ignore the blow of bribery crimes", the focus of criminal blows is bound to shift. The criminal policy of "Punishing implementing bribery is as important as taking bribes" has not been effectively implemented. The high-pressure situation of punishing bribery crimes is difficult to comprehensively form.

\section{The Method of Reduction of Corruption Crimes in the Field of Government Procurement in China}

\subsection{Construction of Front-End Prevention Mechanism: the Chinization Idea of the Disqualification Mechanism}

The Disqualification mechanism in the field of foreign government procurement is more targeted and applicable in the field of government procurement than the blackmail system and the bribery crime file query system in China, and the localization of the Disqualification mechanism is most appropriate. The idea is based on China's existing blacklist system and the bribery crime file query system, combined with the useful experience of the foreign Disqualification mechanism and the actual situation in China's government procurement field, increasing the applicability of the cancellation mechanism in the field of government procurement in China.

The basic concept of the Disqualification mechanism: "treating the sick and saving people" instead of "all in one place". Looking at the existing front-end prevention mechanism of corruption crimes in China, compared with the foreign Disqualification system, there is a certain degree of difference from the perspective of the construction concept of the system. It is undeniable that the existing front-end prevention mechanism of corruption crimes in China still has more or less the concept deviation of "either good comrades or prisoners". The means of preventing corruption crimes are too strict and rigid, and the basic policy of "treating the sick and saving people" It has not been well reflected in the front-end prevention mechanism of corruption crimes in China. The author believes that to construct a Disqualification mechanism with national characteristics in the field of government procurement in China, the choice of basic concepts should be placed in the primary position. The basic policy of "post-punishment, treatment and rescue" should be taken as the basic concept of the Disqualification mechanism in the field of government procurement in China. To be insisted, the concept of "one place" should be abandoned. The author believes that the so-called "rescue the disease and save people" should regard "rescue" as the fundamental purpose of system design. "Governance" is only the means and means of "rescue", not the fundamental purpose, and simply and rigidly excludes "problem enterprises" from the government. Beyond the scope of procurement, from the perspective of the cost and benefit of crime prevention, the scientific and rationality may be discussed.

Construction of the Disqualification mechanism: focusing on applicable conditions, applicable deadlines, and lifting paths. Constructing the Disqualification mechanism in the field of government procurement in China means that we should get rid of the fragmented state of the existing mechanism, and set up an independent, complete and systematic Disqualification mechanism in the field of government procurement in China. At the same time, we should also pay attention to the inability to leave China. Therefore, combined with the beneficial experience of foreign countries and China's existing exploration, the Disqualification mechanism in the field of government procurement in China should focus on the following three aspects: applicable conditions, applicable time limits and lifting paths.

As far as the applicable conditions are concerned, the author believes that the applicable conditions of the Disqualification mechanism in the field of government procurement in China 
should include two aspects, one is criminal behavior and the other is untrustworthy behavior. From the perspective of criminal behavior, it should be clear that the specific scope of criminal acts applicable to the cancellation mechanism is: The author believes that the criminal behaviors that are included in the conditions for applying the Disqualification mechanism are based on the fairness of the government procurement field, and criminal acts that may affect the fair trade order should be included, including corruption and bribery crimes, crimes of tax collection and management, Drug crime, production and sale of counterfeit goods, smuggling crimes, financial fraud crimes; on the other hand, based on the public nature of government procurement, crimes against national security crimes and terrorist activities should be included. From the perspective of untrustworthy behavior, considering the existing administrative policies and regulations, the provisions on the act of dishonesty involving government procurement are more complicated. The author believes that the legislative model similar to the criminal law of criminal law can be adopted, and the laws and regulations that need to be referenced are directly listed. The four listed examples of government procurement are more typical of dishonesty.

As far as the applicable period is concerned, the author believes that the applicable period of the Disqualification mechanism should be set separately for the criminal behavior and the untrustworthy behavior, so as to achieve a scientific match between the behavioral harm and the applicable period. From the perspective of criminal behavior, it should refer to the provisions of the Criminal Law of China on the time limit for prosecution, and the applicable time limit for the disqualification mechanism of sub-files and sub-divisions. At the same time, regardless of unit crimes or natural person crimes, the conclusion of the natural person's sentencing should be unified as a measure of the applicable period. Standards, where there are multiple natural persons in the same case, the natural person who is sentenced to a heavier penalty shall be the measure of the applicable period. As discussed above, considering the division of the applicable period from the perspective of criminal behavior, the emphasis is on the behavioral hazard and the length of the period during which the Disqualification mechanism is applied. For criminal acts with higher harm, it should be applied to a longer period. The term, and vice versa, should correspond to a shorter period of application. From the perspective of untrustworthy behavior, the act of dishonesty is not criminal. Therefore, it may be considered that it is not necessary to adopt the practice of sub-files of different criminal acts and the period of division of the eligibility cancellation mechanism.

As far as the dismissal path is concerned, the author believes that the dismissal path in the eligibility cancellation mechanism mainly involves the setting of the dismissal condition. According to the two different applicable conditions of the criminal act and the untrustworthy behavior, different cancellation conditions should be set accordingly. For example, in view of the consequences of the cancellation of qualifications caused by criminal acts, you can refer to the provisions of the UK Public Contract Law 2015 to set the conditions for cancellation as "payment or compensation for the consequences of damage caused by criminal acts", which is triggered by acts of dishonesty. The consequences of the disqualification can be set as the "resolving the facts and circumstances for the breach of trust and preventing the recurrence of untrustworthy behavior". In addition to setting the release conditions, it is also possible to consider introducing a third-party evaluation mechanism in the release path to measure the self-check and rectification effect of the enterprise. That is, after the enterprise completes the self-inspection and rectification, whether the enterprise has established a good compliance mechanism at this time is enough to prevent the risk of recurrence of criminal behavior and untrustworthy behavior, and should be evaluated and reviewed by a third-party evaluation agency (such as a law firm). Only when the enterprise passes the evaluation of the third-party evaluation agency and draws a positive conclusion, the enterprise can resume the participation qualification in the government procurement field, otherwise the Disqualification mechanism will continue to be used to exclude the enterprise's participation in the government procurement field. . 


\subsection{Strengthening of Criminal Sanctions at the Back End: Thinking Change and Key Switching of Criminal Justice}

From the perspective of criminal sanctions at the back end, thinking about the reduction of corruption crimes in the field of government procurement, the most urgent task is to change the inertial thinking of criminal justice, strengthen the crackdown on bribery crimes in the field of government procurement, and advocate and implement "punishing bribery and punishing bribery.

Theoretical side: the theory of joint crime requires that both punishing bribery and punishing bribery should be equal. The system of accomplice in the criminal law of our country presents the system characteristics of "double-layer system". The so-called two-tier system, the first layer is different from the division of labor of the common offender, the common offender is divided into the perpetrator, the instigator, the helper to achieve the conviction evaluation of the joint offender, the second layer is the joint criminal The role of crime is different, and then the main offender and the offender are distinguished to achieve the penalty for the joint offender. In the two-tier system of accomplice, the first layer can be used to solve the conviction evaluation of bribery crimes, and the second-tier settlement of the crime of bribery crimes can not of course conclude that bribery crimes are lighter than bribery crimes. The role of bribery crimes and bribery crimes in the same accomplice relationship needs to be judged on the basis of the specific case, and the same effect is the usual performance of the two in the same accomplice relationship. From this point of view, from the theoretical perspective, the punishment of bribery crimes and bribery crimes is an inevitable requirement of the criminal law of criminal law in China. The criminal policy of "punishing bribery and punishing bribery" should be implemented and adhered to.

Practice side: breaking the interest alliance requires bribery and bribery crimes. In practice, because both bribery and bribery are criminal, and the hidden characteristics of bribery crimes, it is easy for bribers and bribers to have interests and alliances, and the difficulty of criminal justice against bribery is increased. . Under the criminal policy of "taking bribes and bribery", the bribers use the criminal policy to punish the bribery crimes after committing bribery, and are free from the criminal law network. At this time, the criminal policy of "taking bribes and bribery" is tantamount to playing the "incentivist" role of bribery crimes, the bribers who escaped from the criminal law network can continue to carry out bribery without fear, and the social concept of "taking bribes and committing bribes without sin" is also formed. From this point of view, starting from the practical side, breaking the alliance of interests between bribery crimes and bribery crimes, we should persist in and vigorously advocate the criminal policy of "punishing bribery and punishing bribery."

The author believes that changing the criminal justice inherent thinking, insisting on and vigorously advocating the criminal policy of "punishing bribery and punishing bribery and paying equal attention" can focus on two aspects: on the one hand, from the perspective of ideological understanding, criminal justice should be soberly aware that bribery The role of crime as a "cause" in bribery crimes, and the role of the "fruit" that bribery crimes usually play, severely punish bribery crimes according to law, is the medicine that fundamentally suppresses bribery crimes; From the perspective of law enforcement and handling cases, we should abandon the isolated case thinking of bribery crimes, combine the bribery crimes in the same accomplice relationship with the crime of accepting bribes, uniformly deploy, strictly enforce the judiciary, and simultaneously investigate and deal with bribery crimes and bribery crimes. Therefore, the alliance of interests between bribery crimes and bribery crimes can be effectively cracked.

\section{References}

[1] "Prevention of "Government Procurement Corruption Cases" Experts Say Implementation Regulations Urgently to Be Released", available on Renmin.com, http://leaders.people.com.cn/GB/12663026.html, accessed on August 15, 2018.

[2] "Corporate Procurement Corruption Risks and Prevention Strategies (I)", published in the Chinese Government Procurement Network, http://www.ccgp.gov.cn/dfcg/llsw/201511/t20151118_6159794.htm, August 15, 2018 access. 
[3] Sope Williams-Elegbe, Fighting Corruption in Public Procurement (United Kingdom: Hart Publishing Ltd, 2012), pp. 31-33.

[4] "Development and Reform Commission on the credit red and black list system for comments: will be unified standards", ZAKER, http://www.myzaker.com/article/5924bb6a1bc8e0401300000a/, July 31, 2018 visit.

[5] Feng Yi: "Government Procurement Becomes the Main Field of National Bribery Crime Archives Query System”, China Government Procurement Report, 1st edition, July 19, 2013.

[6] Yu Zhigang: "The Construction of China's Criminal Record System and the Systematic Integration of Judicial Resources--From the Perspective of the Supreme People's Procuratorate's "British Bribery Archives Query System"), in Jianghan Forum, No. 3, 2016.

[7] Chen Yuxia, Liu Ying: "Discussion on the Archives System for Bribery Crimes", in the “Fujian Forum • Humanities and Social Sciences Edition”, No. 12, 2009.

[8] Wang Yi: "Analysis of the Path to Promote the Construction of the Blacklist System of Social Organizations' Loss of Trust”, in the 4th issue of Dalian Cadre Journal, 2017.

[9] Qi Jianlin, Bai Simin: "System Improvement of Archives of Bribery Crimes”, in the "People's Procuratorate”, No. 1, 2015.

[10] Gao Chenggang: “The Effectiveness of Bribery from the Perspective of Empirical Research”, in Politics and Law, No. 5, 2016.

[11] Yu Hong, Deng Chunhua: "Investigation on the Non-criminalization of Bribery-Based on the Solution of the Relationship between Bribery and Bribery in Practice”, in Journal of Jiangsu Police Academy, No. 4, 2009.

[12]Liu Renwen: "Peeling Bribery and Punishing Bribery Should Pay Equally" is contained in the 6th edition of the People's Court Daily on July 18, 2018.

[13] Miao Youshui: "Why advocate "punishing bribery and punishing bribery and paying more attention" - reading Li Shaoping's article on the law enforcement of bribery crimes and its countermeasures> is in the sixth edition of the People's Court Daily on May 8, 2015.

[14] Li Shaoping: "The Plight of Law Enforcement of Bribery Crimes and Its Countermeasures", in the first issue of China Law, 2015. 